\title{
Pre-Service Teacher Training, Primary Teachers’ Identities, and School Work
}

\author{
Amélia Lopes, Rafael Tormenta \\ University of Porto ${ }^{1}$, Centre of Research and Intervention in Education ${ }^{2}$, Portugal
}

\begin{abstract}
Given the importance of primary education as a basis for a knowledge society, the aim is to contribute towards improving the effects of preservice teacher training, in terms of lifelong learning and professional efficacy. We present the results of research carried out with the aim of relating preservice training curricula and the construction of teacher identities. Forty biographical narratives were collected from primary school teachers who had trained at the same pre-service teacher training college in 4 different periods over the last 40 years. The results suggest that pre-service training has a real impact on identities, but also that a large part of that impact is neutralised in the work contexts. Here, a traditional conception of school work persists which forces new teachers to adapt to the real schools. These results are discussed in relation to the challenges posed by the knowledge society.
\end{abstract}

\section{Introduction}

Children's first years of school are a period in which conceptions and ways of accessing knowledge, as well as the connected cognitive, affective and social processes, are constructed and transmitted. Therefore, developing new ways of training basic education teachers is an issue that has concerned several theorists, educational system administrators and international agencies dedicated to schooling.

Actually, if we accept that the "knowledge society" is developing, we must also consider that primary school teachers are key players in building a world in which the decisive issues of efficiency and productivity are well-matched with the communicational questions of human training and ordinary life. On the route toward the knowledge society the training of primary school teachers in new ways is, therefore, an important dimension to invest in.

However, training primary school teachers has revealed difficulties in transforming teaching practices, which have been built up throughout years of organization of mass teaching processes. The gap between the challenges presented at that teaching level by the knowledge society and the real practices taking place in it is, the majority of times, something to be questioned.

In this paper we intend to discuss the training of teachers of the first stages of the educational system focusing on the construction of professional identities.

With Claude Dubar [1] we look at the construction of professional identities as a process that conforms to a double transaction - the biographical, of the subject with him/herself, between who he/she has been and wants to be; and the relational, between the subject and what is offered in the training and work contexts, 'offers' that can challenge or inhibit the ways he/she wants to be.

Professional identity is both individual and collective. As an individual identity it is one of the social identities of the person and corresponds to the combination of the ideal of oneself in the social role, as a function of the possibilities available in the culture [2]. The collective identities correspond, on a societal level, to representations of the profession shared by groups and, at an organisational level, to a joint action where different identities are articulated in a specific way to act together [2].

If the biographical transaction emphasises the individual identity, the relational transaction draws attention to the relationship between individual identity and the collective identities possible in the field of action. When there is a mismatch between them, individual identities develop assimilation or accommodation strategies, aiming to reduce the divergence, transforming themselves in order to adapt to the contexts, or changing the contexts to adapt them to themselves.

The meeting of the individual perspectives and characteristics and the collective possibilities of being give rise to what Dubar [1] refers to as "identity forms", which result from the interactions between the person and the institutional, social, or organizational structures as a function of identification, differentiation and opposition processes. Identity forms are limited in number and correspond to the possible social positions where different subjects are brought together.

As interpretative communities and places of collective action, work places can, therefore, integrate various identity forms, at the same time 
stable and renewable. The existence of several possibilities of being, by avoiding polarisation or stagnation, is a condition for improvement and progress [3]. However, in plural societies the tendency for the possible points of view to be reduced to one or two (where one is, explicit or implicitly, the antithesis of the other) persists (and sometimes increases), limiting the possibilities of individual fulfilment and impoverishing the fields of activity they relate [4].

The construction of the professional identity of a teacher begins even before pre-service training and develops during pre-service training and throughout the professional trajectory, as a function of the desires and personal conditions of the teacher (biographical transaction) and of the challenges or obstacles in the contexts in which the teacher operates (relational transaction). We have used the term "psychosocial identity" to refer to the identity of the teacher when the teacher enters pre-service training [5]. In the choice of profession, for example, there are dimensions of personal identity associated with representations of the profession, which lead the individual to choose this profession rather than another one. It is this identity that will be transformed during pre-service training, giving rise to the "basic professional identity" [1], the identity of the teacher after completing the training. It is this basic identity which will be put to the test in the work contexts, at the beginning and throughout the professional career, giving rise to, at each stage of that career, the "current identity" of the teacher.

According to Claude Dubar [1], the basic professional identity is part of the biographical transaction and is a generational problem. For the same author, it can be identified from the professional illusions and disillusions throughout the professional career: if the identities proposed by the systems of action should be analysed with reference to the activity being studied, the real identities inherent to the biographical transaction can only be analysed through the trajectories of individuals, as reported by them.

Aiming to contribute towards improving the effects of pre-service teacher training, a research was carried out focusing the impact of pre-service training curricula and school work on primary teachers' identities construction.

Biographical narratives of teachers were collected through semi-structured interviews. As Bolívar, Domingo and Fernandez [6] mention, personal dimensions "can only be expressed through narratives", where "the social is psychologised and the psychic is socialised".

Interviewed teachers had their initial training at the same institution (in an important Portuguese urban centre) at four different historical moments: the first half of the 70s (before the democratic revolution), the second half of the 70s, the 1980s and the 1990s. In the first period, the curriculum is quite poor (pedagogic, scientific and practical training is very incipient) and pre-service training takes place over two years in Normal Schools. The second period involves huge changes in pre-service teacher training in Portugal as a result of the democratic revolution and is grounded in the dignification of teachers as professionals; the course has a stronger pedagogic, scientific and practical component, lasts for 3 years and takes place in Normal Schools. The third period covers a transition stage where the objective characteristics of the course in the previous period are maintained, but now without the enthusiasm of the revolutionary period; training lasts for 3 or 4 years, first in Normal Schools and then in Teacher Training Colleges. In the fourth period, initial training lasts for 3 or 4 years in Teacher Training Colleges; educational sciences, namely through the constructivist and socio-constructivist perspectives, have a strong influence on the curriculum.

40 teachers were interviewed (10 from each historical period), which had a minimum of three years of teaching and a maximum of 33 years of teaching.

In the biographical approach, the temporal dimension is unavoidable, since lived experience is contextualised in a diachronic manner. The meaning attributed to events can therefore only be understood in relation to the story (to one story).

Therefore, the interview was organized having as fields the different personal and professional periods of the interviewees' lives - the path before the training, the period of the initial training and the path after the initial training.

\section{Analysis and interpretation}

Once they had been transcribed, the interviews were subject to contents analysis. The resulting coding system is organised into 3 time categoriesbefore the choice of the pre-service training course, the choice of the course and pre-service training and professional career after pre-service training - which were subdivided into subcategories.

The coding and description of the discourses gave rise to dimensions, and we selected 4 for their relevance for the discussion: the choice of the profession; the basic professional identity; the first years and professional socialisation; school work and the relevance of training.

\subsection{Choice of profession}

The choice of the course sheds some light on the representations of the course and of the profession in society and the social and of psychological characteristics of the individuals that choose it. In the case of the teachers interviewed, the choice of the 
course, in almost half of all cases, corresponded to a process of social ascent. The training course for some student teachers, whether in 'Escolas Normais' or in higher education institutions, becomes attractive given the prestige that is given to the profession when associated with the conditions of access, study and professional exercise, considered, particularly in the first period, easy and appropriate for women.

“[...] we [the brothers] were also steered towards the school, to become teachers. There were some family influences in that direction.” (Interview nr. 33 , course of 65/67)

“[...] you either went to University [...] or entered the Teaching Profession. So we would think: 'Well, the teaching profession is the quickest', perhaps it was the less demanding, and off I went to train to become a teacher." (Interview nr. 39, course of 70/72).

“[...] when my mother remarried, my sisters and I [...] said: 'Let's finish a course quickly so we can work'. It was a sort of family rebellion.” (Interview nr. 40, course of 70/72).

“[...] I thought it interesting, because they had 3 months holidays [...].” (Interview nr.35, course of 71/73).

"[...] the parents said: «Look, you go because it is a nice course for a girl»" (Interview nr 30, course of 72/74).

It is not surprising that, about half of the interviewees indicate having chosen the profession feeling a complete absence of vocation. However, a higher number of references to vocation appear as the choices based on criteria of easiness diminish, which happens progressively throughout the training periods analysed.

"I always wanted to be a teacher, so, then already [primary school] I would say that I wanted to be a teacher, I remember I would pay a lot of attention [to my teachers] and identified [with them]. (Interview nr 21, course of 93/97).

Throughout the training periods analysed, there was also an increase in statements showing that in their process of choice of profession some teachers were influenced by the examples of good or bad teachers, through processes of identification, differentiation or opposition, and by the desire to change the school.

"I had only one teacher from the first till the fourth year, she was the director of the school, she was a person... I can say she is my idol, she has always been, I think since I was six years old the only thing I wanted to be was primary school teacher, I never considered being anything else [...] a lot because of her influence [...]." (Interview nr 17, course of 73/75).

"According to the ideals of the time, the school was something to transform. There was also, on my part, that whole rebellion of the past, of thinking that the school had to be changed, the school needed new ideas.” (Interview nr 27, course of 78/81).

In short, the data indicate that elevating the level of training when associated to forms of recruitment and selection that minimize the choices based on easiness increases the number of choices by 'vocation' or associated with a more demanding representation of training and the profession. It therefore shows that there were substantial improvements at this level during the years analysed.

\subsection{The basic professional identities}

For teachers who received their training in different periods, four different basic professional identities were identified: a) identity centred on an education of austerity and conformism type, b) the identity centred on the professional who is the affective and transforming type, c) the identity centred on an education of a type which is technicalaffective and innovative and d) the identity centred on the learning of a cognitive and civic type.

a) These teachers define their activity above all on the task of teaching in the primary school, which they perform in an atmosphere of austerity. There exists an awareness of the existing relation between the environment of training that is undergone, which is this type of education, and an authoritarian society.

"[...] I was a dictator teacher, at the beginning." (Interview nr.33, course of 65/67).

"[The students] had more respect for the teacher [than today]. No doubt about it! It was the teacher and the parish priest [...], they were much respected figures.”

(Interview nr. 7, course of 70/72).

"[...] there were teachers who were already at the school, and we, as we were younger, I [...] let myself be influenced a bit by the ones who were already there. [...] even in the early days of my career, I would hit the students because that was... Before the 25th of April people used to hit the kids... [...]" (Interview nr. 39, course of 70/72). 
"[...] I used to be stricter than I am now." (Interview nr. 35, course of 71/73).

b) This identity seems to have been constructed in opposition to the identity of the previous period: the affective environment in the place of austerity and the transformation in the place of conformity. The transforming dimension appears here to be a product constructed in the training relationships, where the focusing on the child is associated with social change: it is about improving the conditions of life and expression of the most disfavoured children. Teachers trained in this period base their identity on the awareness of the necessity to dignify their profession and on their lifelong learning.

“I didn't [give up on any ideals], I'm always aiming for the best and, therefore, I feel that every day I try and do my best [...]. The idea I had of the profession and what I want to do, the objectives [...], the ideals remain. [...] The school I idealised thirty years ago is still not a reality and that school I idealised is increasingly necessary [...], a school with various teachers, where there's this exchange of experiences.” (Interview nr. 17, course of 73/75).

"[...] being up to date, we are always ready for anything. And this updating is not just a linear updating, updating has to be comprehensive [...]. It's a profession that requires people to constantly update themselves, that they be alert." (Interview nr. 11, course of 74/76).

"I think that the main thing that [pre-service] training gave me was the desire to know more, I acquired that spirit of wanting to know more, and that being a teacher is not static, that it changes with us, with the kids and with things that others discover, and I've always had this idea of knowing something more.” (Interview nr. 2, course of 76/79).

"I think this is what it means to be a teacher. This relationship I establish [with the students], and then the family, because I worry about the child who is not just my student, but is also a citizen of the future.” (Interview nr. 3, course of 76/79).

c) This identity is once again centred on the teacher as someone that teaches but who is also concerned about improving this task and taking care "to be present" in the pupils' lessons: by trying to master the instruments of education related to learning and creating a climate of pleasant learning. The references concerning innovation and education for values in this identity are part of the mainly instrumental position that distinguishes this identity, but bear little relationship to the awareness of the social relations underlying the educational relationship.
"[It's important] that students learn, that they know [...] I think that's what's important, it's the students learning." (Interview nr. 12, course of 78/81).

"[...] I thought, at the beginning of my career, that I'd be teaching the children to read and write, that I was not a good teacher if they got to the end and didn't know all those things I had to teach them." (Interview nr. 14, course of 82/85).

"[...] and it's the wanting to have reading and writing, and maths, playing a major role [...]. And that idea that you have a job to do, which is important, that in a second year a child should master, minimally, the reading technique, were always present. I always thought, combining what was a requirement of a school that imposes a very closed curriculum, with what I also thought was important, in terms of complementing that curriculum, which was to give my students the opportunity of doing a lot of art, a lot of physical education [...]" (Interview nr. 26, course of 77/80).

"I think it's all important, because both the relationships established and the conveying of knowledge play a role, [...] following the programme, naturally, and trying to convey that knowledge that is prescribed in the curriculum, but also thinking of developing other capacities [...]. [Conveying values] increasingly makes more sense, because I think that increasingly [more] there is a bit of a lack of values.” (Interview nr. 13, course of 85/88).

d) These teachers see their teaching activity more in the light of the learning to be carried out by the pupils rather than according to what the teacher has to teach them. The aim is that the pupils acquire the capacity and the will to learn. Here one feels a strong influence from the constructivist perspectives in the formulation of the model of this identity. The relation with society seems now to assume a greater sense of consistency, with references to education for citizenship and democracy, but as an extension of a scientific representation of the teaching-learning process and not as a conscientious decision about the social relation underlying the educational relationship.

"Most important, firstly, is [...] that they learn. And at the same level, to have a good relationship with them, knowing that apart from being a teacher I can be a friend, I can listen to them, I can help them. And another important thing is the fact that I feel fulfilled. For me that counts a lot.” (Interview nr. 8, course of 90/94). 
"[The most important thing] is to give [the students], essentially, a panoply of situations in which they can position themselves more in one or another [...], essentially, to awaken... my values are my values, what I try is for each one of them to build their own values of democracy, justice, critique.” (Interview nr. 18, course of 93/97).

"[...] especially [the] part, not so much of teaching them to read and write, that's important and that's what we have to respect, but especially [the part of] teaching people to live with each other and to get along.” (Interview nr. 1, course of 97/00).

The basic professional identities identified show that pre-service training can make a difference and also that, if we consider the testimonies of the teachers who trained in the different periods, preservice training has improved, although it has not always been measured against the same benchmark.

\subsection{The process of socialization of teachers: training and first years}

The transition from the situation of student to a professional situation comes as a decisive stage in the passage of life of those interviewed, given the contradictions between the conceptions of education propagated by the training period (evident in the visions of oneself as a person and as a professional at the end of the training) and professional practice. This discrepancy leads teachers who are at the beginning of their career to adopt strategies of survival and control, generating a lack of investment in their profession, above all if the idealized future and/or the representations of the ideal school that they still possess vanishes and in its place appear disenchantment, insecurity and the consequent routine nature of teaching:

"When leaving the course I had certain expectations that I didn't achieve at all! [...] My greatest anguish is to have to give up or to relegate some of my ideas to second place if I find that I am not going to carry them out and to verify that there is some contradiction between what I do and what I think.” (Interview nr. 9, course of 78/79).

"I was very lonely and the distance between what I experienced in the initial training and the reality that I had to face was so frightening that I didn’t know what to do, except put my head between my hands!” (Interview nr. 12, course of 80/81).

"I had to change the idealistic vision that I had of the profession." (Interview nr. 5, course of 93/94).
"I left with some ideals, some of which I had given up on. Some adaptations had to be made!" (Interview nr. 8, course of 95/96).

It is worth emphasising that the more demanding the training (both in pedagogic and in scientific terms), the larger the shock of reality will be. In effect, the 2nd and 4th periods are the ones where the shock of reality is most evident. In the 1st period, it is not mentioned by any teacher.

\subsection{School work and the relevance of training}

In the interviews, teachers highlighted the longlasting importance of their first experiences. In general, to deal with the "shock of the real" [7], the teachers disclosed that their training, referring to the theoretical-practical knowledge learned in the Teachers' Training Courses, was not enough. So they then had to make use of the school culture in the place they were working.

The analysis makes it clear that, soon after their professional initiation, the basic professional identity undergoes a process of re-composition that varies from one person to another. In general, the construction of the teaching profession, and consequently of their professional identity, seems more than anything to fit into an informal, individual, intuitive process, carried out in the day to day activity, that is to say fundamentally in terms of the pedagogical relationship in the context of classroom (the resource that Montero Mesa [8] designates by latent models) and in the contact with their peers (in explicitly rewarding situations, most of them in situations of discrete suffering). Relations with children is the main source of attachment to a profession that, in practice, is economical with specific professional knowledge to their profession, to adopt the traditional forms of pedagogical work that continue to characterize school cultures, to which are associated traditional concepts about school knowledge.

Apparently, in a related manner, the interviewees from all periods tend to find that pre-service training had little value. Actually, the interviewees devalue the formal curriculum in their training which they perceive in terms of subjects.

Nevertheless, the informal curriculum is the one they effectively recognize as having had a training result. Informal curriculum concerns especially learning that happened outside the classroom, even though, here and there, it also regards learning that took place in the classroom. Those resulting from the peer group, from teaching reflection meetings between teachers and students, from areas of the curriculum not considered to be subjects (disciplines) and those intrinsic to the teaching-learning process in classes are the ones that stand out. In general, for the 
interviewees, the 'value' of their initial training is connected with its practical character, concerning the experience of teaching children (internship, autonomy in the teaching practices, going beyond the plan), the ways of teaching-learning, the areas of expression and the professional/academic character of the training (centred or not in the profession). The relevance of the training for the contexts of action is considered higher by those trained in the revolutionary period (professional training) and lower by those trained in the 1990s, indicating that the integration of teachers training in higher education institutions made the training more academic.

\section{Conclusion}

Two aspects show up from the results: on one side the way ideas and practices transmitted in training and by social changes affect the construction of the identities of the teachers; on the other, the manner in which that impact of training on identity is wasted in the work contexts.

In most schools, there persists a collective identity that corresponds to a single identity form, which is still guided by traditional work practices. There appears to be a large gap between school work (collective identity) and the basic professional identities (individual), forcing them to adopt a process of accommodation that strips teachers of a large part of the ideals on which their first identity was based.

The distance between training - which is a transmitter of new perspectives - and the real contexts of work - where traditional ways of work prove to be difficult to modify has a parallel in the teachers as people, where the ideal professional and the more down to earth maintain a difficult relationship.

Given our advance towards the information society, it is important to reflect on the construction of primary teachers' professional identities in the context of training and the contexts of work. The results also give us the topics for this reflection. As far as the part of the training is concerned, we should raise the level of training without making it too academic, but instead making it more relevant for the contexts of work. Basic professional identity of the interviewees from the second period analysed is very close to the profile advocated for teachers today definition of the teacher as a professional, capable of lifelong learning [9]. The manner in which they value and define the informal curriculum in preservice training suggests a pre-service training based on the profession, on practice, on learning and on debate. The importance currently given to independent work and project methodologies in higher education is, in this respect, an important opportunity which should not be wasted, especially given that the conditions that information and communication technologies offer today multiply the possibilities, for teachers and students.

With regard to the work contexts it is a question of being bold enough to give up for good conceptions about knowledge, and to adhere to ways which are more active, meaningful and part of the knowledge of daily life.

The manner in which tradition still tends to play a major role in primary education is associated with its long history and to the place that it has occupied in the social division of work. A large part of the organisation of spaces and times in the traditional primary school remains and it is associated with particular forms of behaviour and conceptions of knowledge. The new conceptions of knowledge and of access to knowledge require new organisational forms and new systems of communication between teachers and between teachers and students, which will correspond to new and varied identity forms.

\section{References}

[1] Dubar, C., A Socialização - a Construção de Identidades Sociais e Profissionais [The Socialization Social and Professional Identities Construction], Porto, Porto Editora, 1997.

[2] Lopes, A., La Construcción de Identidades Docentes como Constructo de Estrutura y Dinámica Sistémicas: Argumentación y Virtualidades Teóricas y Prácticas [The Construction of Teachers' Identities as a Construct of Systemic Structure and Dynamic]. Profesorado - Revista de Curriculum y Formación del Profesorado, 11, 3, 2008. http://www.ugr.es/local/recfpro/rev113COL1.pdf.

[3] Lopes, A., Constructing Professional Identities in Portuguese Primary School Teachers - Some Relevant Conclusions of a Study Based on the Interpretative Paradigm. Identity: an International Journal of Theory and Research, 2 (3), 241-254, 2002.

[4] Zavalloni, M., \& Louis-Guerin, C., Identité Sociale et Conscience - Introduction à L'Égo-Écologie [Social Identity and Consciousness - Introduction to EgoEcology], Montreal, Les Presses de l'Université de Montreal, 1984.

[5] See: Lopes, A., Pereira, F., Ferreira, E., Silva, M. A., Sá, M. J., Fazer da Formação um Projecto - Formação Inicial e Identidades Profissionais Docentes [To make training like a project], Porto, LIVPSIC, 2007.

Simões, C., \& Simões, H., Maturidade Pessoal, Dimensões da Competência e Desempenho Profissional [Personal maturity, Competence Dimensions and Professional Performance], in I. Sá-Chaves (Org.), Percursos de Formação e Desenvolvimento Profissional [Training Paths and Professional Development], Porto, Porto Editora, 1997, pp. 37-57.

[6] Bolívar, A., Domingo, J. e Fernández, M., La Investigación Biográfico-Narrativa en Educación, Enfoque y Metodología [Biographical-Narrative Research in 
Education, Focus and Methodology], Madrid, La Muralla, 2001, p. 16.

[7] Lopes, A., Da Formação à Profissão - Choque da Realidade ou Realidade Chocante? [From Training to Profession - Reality Shock or Shocking Reality?], in M. L. Alonso, \& M. C. Roldão, Ser Professor do $1^{\circ}$ Ciclo Construindo a Profissão [To be a Teacher - Constructing the Profession], Coimbra, Almedina, 2006, pp. 85-92.

[8] Montero Mesa, L., La Construcción del Conocimiento Profesional Docente [The Construction of Teachers' Professional Knowledge], Rosario, Homo Sapiens, 2001.

[9] Buchberger, F., Campos, B. P., Kallos, D., \& Stephenson, J., High Quality Teacher Education for High Quality Education and Training, Green Paper on Teacher Education in Europe, Thematic Network on Teacher Education in Europe, Umea, 2000. 